\title{
Pengembangan Modul Berbasis Education for Sustainable Development pada Konsep Ekologi untuk Siswa Kelas X SMA
}

\author{
Aditya Rahman, Lucya Mega Heryanti, Bambang Ekanara \\ Jurusan Pendidikan Biologi FKIP Universitas Sultan Ageng Tirtayasa \\ adityauntirta@gmail.com
}

\begin{abstract}
This research aimed to develop a product and to find out its eligibility and students's response of module based education for sustainable development (EfSD) on ecology concept for X grade students. Research and development $(R \& D)$ method with Dick \& Carey model was used in this research. It consisted of 5 stages, that were Analysis, Planning, Development, Formative Evaluation, and Revision. Instrument validation was assessed by experts (concept, media and teachers). According to the result of expert assesment, the module earned score 94\%. The score was included into very decent category. The score of students's response was $84,4 \%$. The score was included into very worth category. It can be concluded module based EfSD on ecology concept for X grade students was very decent for learning material.
\end{abstract}

Keywords: Learning Module, Education for Sustainable Development, Ecology.

(i) This is an open access article distributed under the Creative Commons 4.0 Attribution License, which permits unrestricted use, distribution, and reproduction in any medium, provided the original work is properly cited. $@ 2018$ by author and Universitas Negeri Padang.

\section{PENDAHULUAN}

Bahan ajar merupakan materi pembelajar an yang disusun secara sistematis dan digunakan dalam proses pembelajaran oleh guru dan siswa (Sadjati, 2012: 5). Bahan ajar yang berkualitas akan mendukung tercapainya pembelajaran yang efektif dan efisien. Menurut BSNP (2010), terdapat beberapa kriteria bahan ajar yang berkualitas, yaitu mengacu pada kompetensi dasar, berisi pengetahuan tertulis sesuai dengan tahap kognitif siswa, berisi konsep-konsep yang disajikan secara interaktif dan menstimulus adanya proses berfikir kritis serta kreatif, dan tampilan yang disajikan menarik.

Hingga saat ini, bahan ajar yang digunakan guru di sekolah adalah buku paket dan LKS. Hal ini terlihat dari hasil penyebaran angket analisis kebutuhan di tiga sekolah di Cilegon, yaitu SMAN 1 Cilegon, SMAN 3 Cilegon, dan SMA Raudhatul Jannah. Materi yang disajikan dalam bahan ajar tersebut sudah sesuai dengan kompetensi dasar yang harus dicapai oleh siswa namun, materi yang disajikan tidak menunjukan adanya konsep pembangunan berkelanjutan. Menurut DRN (2003) konsep pembangunan berkelanjutan penting untuk diajarkan di pembelajaran karena konsep tersebut membekali siswa dalam menghadapi tantangan pendidikan di abad 21 ini. Selain itu, konsep ini mampu memotivasi siswa dalam menjalani gaya hidup yang berkelanjutan (Kemendikbud, 2016). Oleh karena itu diperlukan bahan ajar yang mampu memenuhi kebutuhan tersebut, salah satunya yaitu pengembangan modul pembelajaran. Hal tersebut karena modul pembelajaran dapat dirancang sesuai dengan kebutuhan pembelajaran yang diinginkan (Kuswandari et al., 2013: 43).

Modul Pembelajaran merupakan bahan ajar, alat atau sarana pembelajaran yang disusun sedemikian rupa berisi materi, metode, batasanbatasan materi pembelajaran, petunjuk kegiatan belajar, latihan dan cara mengevaluasi pembelajaran (Santoso, 2013: 62). Adapun kelebihan yang terdapat dalam modul pembelajaran dibandingkan dengan bahan ajar lainnya yaitu, penyajian materi tidak terlalu verbal, mengatasi keterbatasan alokasi waktu, meningkatkan motivasi siswa dan siswa dapat mengukur hasil belajarnya sendiri (Depdiknas, 2008).

Menurut KPN (2010), Education for Sustainable Development (EfSD) atau pendidikan untuk pembangunan berkelanjutan merupakan pendidikan yang menyisipkan wawasan secara luas dan futuristik tentang lingkungan global untuk memberi kesadaran kepada masyarakat agar berkontribusi dalam pengembangan berkelanjutan di masa sekarang dan masa depan. KPN (2010) menyatakan bahwa EfSD penting dalam suatu pembelajaran. Hal tersebut karena EfSD menanamkan pemikiran tentang kebutuhan hidup untuk 
generasi sekarang tanpa harus mengesampingkan masa depan. Modul pembelajaran ekologi yang memuat pembangunan berkelanjutan memiliki kelebihan dibandingkan dengan modul lainnya yaitu, siswa tidak hanya belajar tentang lingkungan saja, tetapi siswa juga belajar tentang sosial, tanggung jawab sebagai warga negara, sehingga siswa mampu berpikir secara global (Segara, 2015: 24). Oleh karena itu, pada penelitian ini akan dikembangkan modul pembelajaran berbasis EfSD pada konsep ekologi untuk siswa SMA Kelas X. Penelitian ini bertujuan untuk menghasilkan modul berbasis EfSD pada konsep ekologi untuk siswa kelas X SMA dan mengetahui kelayakan modul berbasis EfSD pada konsep ekologi untuk siswa kelas X SMA.

\section{METODE PENELITIAN}

\section{A. Definisi Operasional}

1) Modul berbasis Education for Sustainable Development dalam penelitian ini dikembangkan untuk menghasilkan bahan ajar yang memuat karakteristik dari EfSD yaitu Envisioning, Critical Thinking and Reflection, Participation in Decision-making, Partnerships, dan Systemic Thinking. Pengembangan modul ini menggunakan metode $R \& D$ dengan 5 tahapan dari model pengembangan Dick \& Carey yaitu Analisis, Perencanaan \& Penilaian Instrumen, Pengembangan, Evaluasi Formatif dan Revisi.

2) Konsep Ekologi merupakan konsep yang dipelajari oleh siswa SMA kelas $\mathrm{X}$ semester 2. Kompetensi dasar yang digunakan dalam konsep ini yaitu 3.10 "Menganalisis komponen-komponen ekosistem dan interaksi antar komponen tersebut" dan 4.10 "Menyajikan karya yang menunjukkan interaksi antar komponen ekosistem (jaring-jaring makanan, siklus biogeokimia)"

\section{B. Waktu dan Tempat}

Waktu dan tempat pelaksanaan penelitian dimulai dari bulan Desember 2017 sampai dengan Oktober 2018 di SMAN 1 Cilegon, SMAN 3 Cilegon, dan SMAIT Raudhatul Jannah.

\section{Teknik Pengumpulan Data}

Teknik pengumpulan data menggunakan angket. Aspek yang dinilai, teknik dan responden dalam angket tersebut dapat dilihat pada Tabel 1.
Tabel 1 Teknik pengumpulan data

\begin{tabular}{llll}
\hline No. & Aspek & Teknik & Responden \\
\hline 1 & Materi & Angket & $\begin{array}{l}\text { Ahli konsep dan } \\
\text { guru }\end{array}$ \\
\hline 2 & Media & Angket & $\begin{array}{l}\text { Ahli media dan } \\
\text { guru }\end{array}$ \\
\hline 3 & $\begin{array}{l}\text { Respon } \\
\text { siswa }\end{array}$ & Angket & $\begin{array}{l}10 \text { Siswa kelas } \\
\text { X SMA }\end{array}$ \\
\hline
\end{tabular}

\section{Teknik Pengolahan Data}

Teknik pengolahan data dari data yang telah diperoleh akan dianalisis secara deskriptif. Kriteria pemberian skor untuk uji ahli (Tabel 2) dan respon siswa (Tabel 3) sebagai berikut:

Tabel 2 Kriteria Pemberian Skor Uji Ahli

\begin{tabular}{lc}
\multicolumn{1}{c}{ Nilai } & Skor \\
\hline Sangat Baik (SB) & 5 \\
\hline Baik (B) & 4 \\
\hline Cukup (C) & 3 \\
\hline Kurang (K) & 2 \\
\hline Sangat Kurang (SK) & 1 \\
\hline
\end{tabular}

Tabel 3 Kriteria Pemberian Skor Respon Siswa

\begin{tabular}{|c|c|}
\hline Nilai & Skor \\
\hline Sangat Setuju (SS) & 5 \\
\hline Setuju (S) & 4 \\
\hline Netral (N) & 3 \\
\hline Kurang Setuju (KS) & 2 \\
\hline Sangat Tidak Setuju (STS) & 1 \\
\hline \multicolumn{2}{|c|}{$\begin{array}{l}\text { Dari data yang telah diperoleh denga } \\
\text { pengukuran skala Likert akan diberi sko } \\
\text { kemudian skor akan diubah menjadi bentul } \\
\text { persentase (Tabel 4) pada tiap aspek penilainy } \\
\text { dengan rumus berikut: }\end{array}$} \\
\hline
\end{tabular}

$\mathrm{NP}=\frac{R}{S M} \times 100 \%$

Keterangan :

$\mathrm{NP}=$ Nilai Persentase

$\mathrm{R} \quad=$ Jumlah skor

SM = Skor Maksimal

[Purwanto, 2008: 102] 
Tabel 4 Skema penilaian uji kelayakan modul

\begin{tabular}{ll}
\hline Persentase & Kriteria \\
\hline $0 \%-20 \%$ & Sangat Kurang Layak \\
\hline $21 \%-40 \%$ & Kurang Layak \\
\hline $41 \%-60 \%$ & Cukup Layak \\
\hline $61 \%-80 \%$ & Layak \\
\hline $81 \%-100 \%$ & Sangat layak \\
\hline
\end{tabular}

[Riduwan, 2010: 89, Modifikasi]

\section{1) Tahapan Analisis \\ a. Analisis kebutuhan}

Berdasarkan hasil penyebaran angket analisis kebutuhan didapatkan bahwa bahan ajar yang digunakan dalam mengajar konsep ekologi yaitu $100 \%$ buku paket, 66,7\% LKS, dan 33,3\% modul pembelajaran. Berdasarkan hasil tersebut dapat dilihat bahwa penggunaan modul pembelajaran jika dibandingkan dengan penggunaan bahan ajar lainnya yaitu hanya sedikit yang menggunakan modul dalam pembelajaran, hal ini sejalan dengan pernyataan Purnomo (2013: 61) bahwa masih sedikit modul pembelajaran yang dipakai guru karena selama ini hanya sedikit guru yang membuat modul pembelajaran untuk proses belajar mengajar.

Adapun dalam penelitian ini, modul pembelajaran dikhususkan pada konsep ekologi berbasis EfSD. Sebanyak 66,7\% guru belum mengetahui tentang EfSD karena menurut guru belum ada sosialisasi tentang itu, hal ini sejalan dengan pernyataan Sungkowo (2005) bahwa sosialisasi tentang EfSD masih kurang, pola pelatihan belum efektif karena kepala sekolah yang telah mendapatkan pelatihan kurang mensosialisasikan ke guru-guru.

\section{b. Identifikasi tujuan pembelajaran}

Identifikasi tujuan pembelajaran di dalamnya mencakup analisis kurikulum. Pengembangan modul pembelajaran mengacu pada kurikulum yang digunakan yaitu kurikulum 2013 (Kemendikbud, 2017).

\section{c. Analisis materi}

Materi ekologi mengacu pada buku paket Biologi SMA/MA kelas X karangan Ririn Safitri dan Bowo Sugiharto. Materi yang akan dimasukan ke dalam modul pembelajaran, yaitu komponen-komponen penyusun ekosistem, pola-pola interaksi dalam ekosistem, aliran energi, dan daur biogeokimia. Pengembangan modul ekologi ini berbasis EfSD, sehingga dalam pengembangannya mengandung 5 karakteristik dari EfSD, yaitu envisioning, critical thinking, partisipant in desicion making, partnership, systemic thinking serta terdapat materi pengantar dan tambahan tentang EfSD.

\section{2) Tahapan Perencanaan \\ a. Menentukan isi modul .}

Isi modul ditentukan dengan cara merancang storyboard. Storyboard ini akan digunakan sebagai acuan dalam pembuatan draft modul ekologi berbasis EfSD, hal ini sejalan dengan pernyataan Purwasasmita (2017: 1) bahwa storyboard dibuat untuk menuangkan ide-ide dalam bentuk visual yang sistematis menjadi acuan dalam membentuk suatu produk bahan ajar.

\section{b. Membuat instrumen penilaian \\ kelayakan modul ekologi berbasis \\ EfSD.}

Instrumen penilaian kelayakan modul ekologi dibedakan menjadi 3, yaitu instrumen untuk ahli materi, ahli media, dan respon siswa.

\section{3) Tahapan Pengembangan.}

Modul yang dibuat oleh peneliti dibantu dengan software desain grafis dan pengolah kata. Bagian cover pada modul berwarna merah bergradasi dengan gambar sesuai konsep ekologi, karena menurut BPPK (2009) modul harus memiliki daya tarik sehingga perlu dilakukan pengkombinasian warna, gambar, bentuk dan ukuran yang serasi. Isi materi yang dibuat peneliti menggunakan pembagian dua kolom dalam badan teks yang berguna agar siswa tidak mudah lelah dalam membaca. Hal ini sesuai dengan pendapat dari Warsinha (2015: 15) bahwa dalam penyusunan modul pembelajaran dianjurkan memakai dua kolom.

Badan teks menggunakan jenis huruf Helvetica karena merupakan jenis huruf sans serif agar siswa tidak keliru ketika membaca, hal ini sesuai dengan pernyataan Sudiana (2001: 330) bahwa huruf Helvetica merupakan jenis sans serif, dan menurut Laksana (2013: 1) Helvetica merupakan jenis huruf yang mudah dibaca.

Modul ekologi ini terdapat informasiinformasi tambahan. Informasi tersebut bertujuan untuk menambah wawasan dan rasa ingin tahu siswa, hal ini sesuai dengan penelitian Rahman (2017:27) bahwa rasa ingin tahu siswa tinggi apabila adanya objek atau peristiwa yang disajikan oleh guru. Informasi tersebut dikemas dalam kotak informasi yang diberi nama "read me!". 


\section{4) Evaluasi Formatif.}

Hasil validasi dapat dilihat pada Tabel 5.

\section{a. Aspek Kurikulum}

Hasil penilaian aspek kurikulum mendapatkan nilai sebesar $100 \%$, menurut Riduwan (2010: 89) aspek tersebut masuk ke dalam kategori sangat layak. Penilaian tersebut didapatkan berdasarkan tercapainya 5 indikator penilaian, yaitu kesesuaian materi dengan kompetensi dasar yang terdapat dalam kurikulum 2013 revisi, pemilihan tujuan sesuai dengan kompetensi dasar pada kurikulum 2013, indikator dijabarkan sesuai dengan kompetensi dasar pada kurikulum 2013, isi modul dapat menambah wawasan pengetahuan siswa, dan isi modul dikaitkan dengan kehidupan sehari-hari.

\section{b. Aspek Kelayakan Isi}

Hasil penilaian aspek kelayakan isi mendapatkan nilai sebesar $90 \%$, menurut Riduwan (2010: 89) aspek tersebut masuk ke dalam kategori sangat layak. Kriteria evaluasi mendapatkan nilai tertinggi, yaitu 95\%, sedangkan ketepatan dan kesesuaian materi mendapatkan nilai terendah dengan nilai $85 \%$. Nilai kriteria evaluasi sebesar $95 \%$ dikarenakan 4 indikator terpenuhi dan terdapat 1 indikator yang menurut ahli belum terpenuhi yaitu kesesuaian soal-soal evaluasi dengan konsep yang disajikan, karena menurut ahli terdapat pertanyaan yang sama pada soal, hal ini sejalan dengan Abdussakir (2006: 10) bahwa dalam membuat soal harus memperhatikan indikator pembelajaran. Nilai kriteria ketepatan dan kesesuaian materi mendapatkan nilai $85 \%$ dikarenakan terdapat ahli dan guru yang berpendapat bahwa modul belum mencapai indikator konsep, definisi, istilah dan contoh yang disajikan akurat. Menurut ahli, pada bagian artikel belum terdapat sumber yang jelas. hal ini diperjelas dengan pernyataan Nurkamto (2010: 14) bahwa sebuah artikel perlu dicantumkan sumber acuannya.

\section{c. Aspek Pendekatan EfSD}

Hasil penilaian dari aspek pendekatan EfSD mendapatkan nilai 90\%, menurut Riduwan (2010: 89) aspek tersebut masuk ke dalam kategori sangat layak. Nilai $90 \%$ pada aspek tersebut didapatkan karena terdapat 1 indikator yang menurut ahli belum tercapai yaitu tentang berfikir kritis yang ada pada kotak informasi tambahan "read me", menurut ahli informasi tambahan tersebut masih berupa hafalan saja.

\section{(1) Envisioning}

Envisioning atau membayangkan merupakan karakteristik untuk siswa mampu membayangkan masa depan yang lebih baik (Gunamantha, 2010: 219). Karakteristik tersebut dituangkan dalam modul pembelajaran yang telah dibuat, yaitu pada sub bab tentang aliran energi. Sub bab aliran energi di dalamnya terdapat sebuah artikel berjudul "Marak Perburuan Liar, Harimau Sumatera Terancam Punah di Bengkulu", berdasarkan artikel tersebut siswa diminta untuk membayangkan hal apa yang akan terjadi jika peristiwa tersebut terus menerus terulang dan mengaitkannya dengan materi rantai makanan yang telah dipelajari oleh siswa.

\section{(2) Critical Thinking}

Critical Thinking (Berfikir Kritis) adalah berpikir secara mendalam tentang suatu hal atau permasalahan yang melibatkan penalaran logis siswa (Kowiyah, 2012: 177). Karakteristik berfikir kritis dituangkan dalam modul pembelajaran pada sub bab EfSD (pembangunan berkelanjutan) dan komponen-komponen ekosistem. Sub bab EfSD di dalamnya terdapat informasi tambahan pada kotak "Read me!", yaitu disajikan sebuah informasi tentang Carbon Emission Trading yang bermanfaat bagi ekonomi Indonesia, kemudian siswa diminta untuk menganalisis manfaat lainnya dalam bidang lingkungan dan sosial dengan diterapkannya Carbon Emission Trading. Sub bab komponen-komponen ekosistem terdapat tugas untuk siswa yang mencirikan karakteristik berfikir kritis, yaitu siswa diberikan tugas untuk menganalisis apakah ekosistem buatan yang terdapat di dekat tempat tinggal siswa mengganggu atau bermanfaat bagi masyarakat sekitar dengan mengaitkan tentang konsep pembangunan berkelanjutan yang telah dipelajari siswa sebelumnya.

\section{(3) Participation in Decision Making.}

Participation in Decision Making atau partisipasi dalam membuat keputusan merupakan karakteristik untuk mengembangkan siswa dalam menganalisis, merencanakan, dan mengatur keputusannya dalam pembangunan berkelanjutan (ARIES, 2009: 3). Karakteristik ini dituangkan dalam modul pembelajaran pada sub bab menjaga ekosistem berbasis EfSD, yaitu terdapat tugas siswa untuk membuat suatu ide inovasi dalam menjaga ekosistem dengan memperhatikan lingkungan, sosial, dan ekonomi. Menurut Tilbury dan Wortman (2004: 
54), karakteristik tersebut memiliki kelebihan, yaitu mendorong pembelajar untuk berbagi pemahamannya, mendeskripsikan makna yang dapat dibangun peserta didik, mendorong kepercayaan diri yang lebih besar atas kemampuan yang dimilikinya, serta mendorong pembuatan solusi terhadap permasalahan.

\section{(4) Partnership}

Partnership atau bekerja sama merupakan karakteristik pada EfSD untuk belajar bekerja sama (Gunamantha, 2010: 220). Menurut Tilbury \& Wortman (2004: 64), permasalahan dalam pembelajaran tidak harus dihadapi sendirian, dengan bekerja sama membantu para peserta didik untuk menciptakan sinergi dalam memecahkan permasalahan mereka. Menurut Rosita \& Leonard (2012: 5) bekerja sama memiliki ketergantungan positif, yaitu tugas kelompok bisa diselesaikan dengan baik apabila terdapat kerja sama yang baik dari anggota kelompok. Tanggung jawab perseorangan, yaitu setiap anggota kelompok memiliki tanggung jawab dalam keberhasilan tugas yang mereka lakukan. Setiap anggota kelompok dapat berkomunikasi dengan baik dengan kelompoknya untuk mencapai keberhasilan yang ingin dicapai mereka. Karakteristik Partnership tertuang dalam modul pembelajaran EfSD ini, yaitu terdapat tugas yang dilakukan secara berkelompok yang terlihat pada kolom "ayo diskusi".

\section{(5) Systemic Thinking}

Systemic Thinking merupakan karakteristik yang dapat membuat siswa untuk mengenali kerumitan permasalahan dan mencari kaitan serta sinergi dalam masalah yang kompleks (Frijters, 2016: 8). Karakteristik EfSD ini terdapat dalam modul pembelajaran berbasis EfSD pada sub bab daur biogeokimia, yaitu ditampilkan sebuah artikel tentang kebakaran hutan yang berjudul "Awal 2018, Kebakaran Hutan dan Lahan di Riau 680 Hektar". Berdasarkan artikel tersebut siswa diminta untuk menganalisis apa yang terjadi jika kebakaran hutan tersebut terjadi secara terus menerus, kemudia siswa diminta untuk mengaitkannya dengan daur karbon yang telah siswa pelajari sebelumnya. Siswa juga diminta untuk menganalisis bagaimana tahapan rehabilitas daur karbon setelah terjadinya peristiwa seperti pada artikel yang disajikan tersebut.

\section{d. Aspek Penyajian Elemen Media Cetak}

Hasil dari aspek penyajian elemen media cetak mendapatkan nilai sebesar $95 \%$, menurut Riduwan (2010: 89) aspek tersebut masuk ke dalam kategori sangat layak. Penilaian tersebut didapatkan berdasarkan rata-rata dari 3 kriteria penilaian, yaitu kriteria dengan nilai tertinggi visual element dan text element sebesar $100 \%$. Nilai $100 \%$ tersebut didapatkan karena menurut ahli dan guru seluruh indikator penilaian sudah tercapai di dalam modul pembelajaran ini, serta kriteria dengan nilai terendah, yaitu Invisible element $85 \%$. Nilai $85 \%$ pada kriteria invisible element didapatkan karena terdapat 3 indikator menurut ahli yang belum tercapai yaitu jarak kolom, tata letak teks dan gambar yang tidak tepat. Menurut ahli, jarak antar kolom terlalu dekat sehingga teks terlihat lebih padat, dan penempatan gambar yang ada pada artikel kurang tepat peletakannya. Hal ini sejalan dengan pernyataan Jiia (2013: 2) bahwa jarak antar kolom dalam kertas A4 sebaiknya adalah 1 $\mathrm{cm}$.

\section{e. Aspek Prinsip Kemampuan Media Menyampaikan Pesan. \\ Hasil dari penilaian aspek prinsip} kemampuan media menyampaikan pesan mendapatkan nilai sebesar 95\%, menurut Riduwan (2010: 89) aspek tersebut masuk ke dalam kategori sangat layak. Nilai 95\% didapatkan karena terpenuhinya 4 indikator penilaian dari aspek tersebut dan terdapat 1 indikator yang belum tercapai yaitu keseimbangan antar element media.

\section{f. Aspek Kebahasaan}

Hasil dari penilaian aspek kebahasaan mendapatkan nilai sebesar $100 \%$, menurut Riduwan (2010: 89) aspek tersebut masuk ke dalam kategori sangat layak. Penilaian tersebut didapatkan berdasarkan kriteria penggunaan bahasa dengan indikator penilaian berupa penulisan sesuai dengan kaidah Bahasa Indonesia dan EYD, penggunaan bahasa sesuai dengan tahap perkembangan siswa SMA, kalimat yang digunakan jelas dan mudah dipahami oleh siswa, penggunaan istilah sesuai dengan bahasa ilmiah, dan kalimat yang digunakan tidak ambigu. Indikator-indikator tersebut terpenuhi sesuai dengan BSNP (2010) bahwa aspek kebahasan perlu diperhatikan dalam pembuatan modul pembelajaran. 
Tabel 5 Persentase Penilaian dan Kriteria Kelayakan Modul Ekologi Berbasis EfSD.

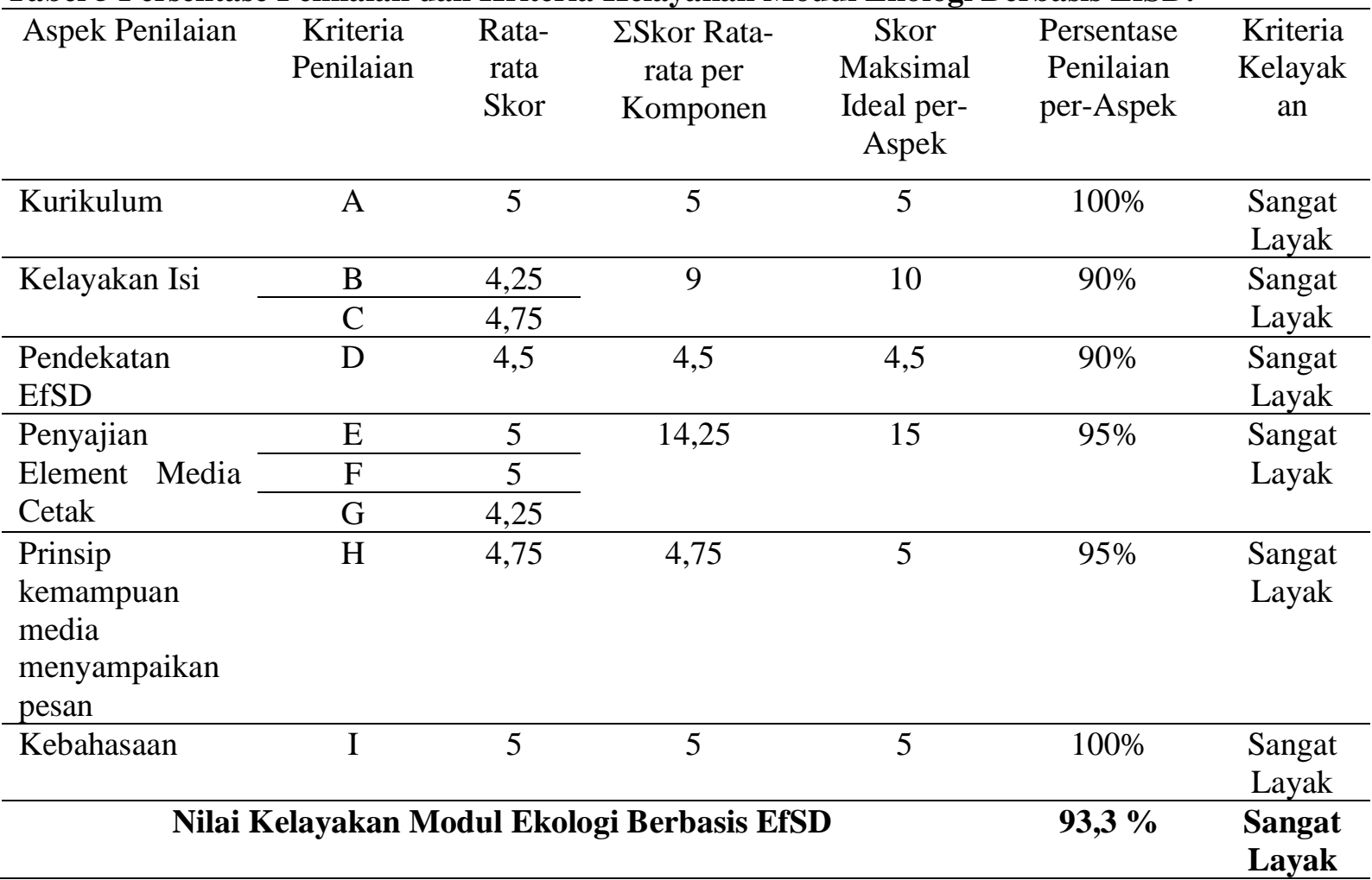

pernyataan Hanifah (2014: 112), ketertarikan

* Keterangan Kriteria Penilaian:

A $\quad=$ Kesesuaian kurikulum 2013 revisi

B = Ketepatan dan kesesuaian materi

$\mathrm{C}=$ Evaluasi

$\mathrm{D} \quad=$ Kesesuaian isi modul dengan karakteristik EfSD

$\mathrm{E} \quad=$ Elemen Visual

$\mathrm{F} \quad=$ Elemen Teks

$\mathrm{G} \quad=$ Invisible Element

$\mathrm{H} \quad=$ Kelengkapan informasi

I $\quad=$ Penggunaan bahasa

\section{5) Tahapan Revisi}

Berdasarkan hasil evaluasi formatif, peneliti melakukan revisi terhadap modul kemudian, dilakukan respon siswa. Hasil tersebut dapat dilihat pada Tabel 6 . Berdasarkan hasil respon siswa, modul mendapatkan nilai sebesar $84,4 \%$ dengan kategori sangat baik.

Aspek ketertarikan mendapatkan nilai $85 \%$ dengan kategori sangat baik. Siswa mengatakan modul ekologi ini menarik sehingga membuat siswa bersemangat dalam belajar dan pembelajaran menjadi tidak membosankan. Hal ini sejalan dengan siswa terhadap modul berguna untuk menarik minat membaca siswa, salah satunya penggunaan ilustrasi-ilustrasi yang menarik sehingga motivasi siswa dalam membaca menjadi tinggi.

Aspek materi mendapatkan nilai $81 \%$ dengan kategori sangat baik. Siswa mengatakan bahwa penyampaian materi di dalam modul mudah dipahami siswa karena bersifat kontekstual. Siswa juga didorong untuk bisa berdiskusi dengan teman-teman lainnya dalam pembelajaran. Hal ini sesuai dengan Muslich (2009: 42) bahwa pembelajaran kontekstual membuat siswa mengerjakan tugas-tugas yang bermakna, menciptakan rasa kebersamaan dalam bekerja sama dan pembelajaran menjadi terintegrasi.

Aspek bahasa mendapatkan nilai $87 \%$ dengan kategori sangat baik. Menurut siswa penggunaan kalimat atau paragraf pada modul mudah dipahami siswa karena kalimatnya sederhana, selain itu juga huruf yang digunakan mudah dibaca. Menurut BSNP (2017), bahan ajar perlu memperhatikan komponen kebahasaan, seperti kalimat yang digunakan harus komunikatif, lugas, dan sesuai dengan kaidah bahasa Indonesia yang benar. 
Tabel 6 Persentase dan Kriteria Kelayakan Modul Ekologi Berbasis EfSD Berdasarkan Respon Siswa.

\begin{tabular}{|c|c|c|c|c|c|c|c|c|c|}
\hline \multirow[t]{2}{*}{ Aspek } & \multirow{2}{*}{$\begin{array}{c}\text { Kompo- } \\
\text { nen yang } \\
\text { dinilai }\end{array}$} & \multicolumn{3}{|c|}{ Sekolah } & \multirow{2}{*}{$\begin{array}{l}\text { Rata- } \\
\text { rata } \\
\text { Skor }\end{array}$} & \multirow{2}{*}{$\begin{array}{l}\text { Skor } \\
\text { Mak- } \\
\text { simal }\end{array}$} & \multirow{2}{*}{$\begin{array}{l}\% \text { Penilaian } \\
\text { Kompo-nen }\end{array}$} & \multirow{2}{*}{$\begin{array}{l}\text { \% Peni- } \\
\text { laian }\end{array}$} & \multirow[t]{2}{*}{ Kriteria } \\
\hline & & 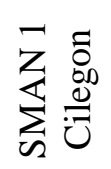 & $\begin{array}{l}m \\
\sum_{0} \\
\sum_{\infty} \frac{0}{0} \\
0\end{array}$ & $\sum_{\infty}^{5}$ & & & & & \\
\hline \multirow[t]{5}{*}{ Ketertarikan } & 1 & 47 & 49 & 37 & 44,3 & 50 & $89 \%$ & \multirow[t]{5}{*}{$85 \%$} & \multirow{5}{*}{$\begin{array}{l}\text { Sangat } \\
\text { Layak }\end{array}$} \\
\hline & 2 & 40 & 43 & 41 & 41,3 & 50 & $83 \%$ & & \\
\hline & 3 & 43 & 40 & 45 & 42,7 & 50 & $85 \%$ & & \\
\hline & 4 & 39 & 40 & 40 & 39,7 & 50 & $79 \%$ & & \\
\hline & 5 & 43 & 46 & 45 & 44,7 & 50 & $89 \%$ & & \\
\hline \multirow[t]{5}{*}{ Materi } & 6 & 45 & 41 & 41 & 42,3 & 50 & $85 \%$ & \multirow[t]{5}{*}{$81 \%$} & \multirow{5}{*}{$\begin{array}{l}\text { Sangat } \\
\text { Layak }\end{array}$} \\
\hline & 7 & 47 & 40 & 48 & 45 & 50 & $90 \%$ & & \\
\hline & 8 & 36 & 37 & 39 & 37,3 & 50 & $75 \%$ & & \\
\hline & 9 & 40 & 39 & 36 & 38,3 & 50 & $77 \%$ & & \\
\hline & 10 & 41 & 40 & 36 & 39 & 50 & $78 \%$ & & \\
\hline \multirow[t]{3}{*}{ Bahasa } & 11 & 43 & 44 & 45 & 44 & 50 & $88 \%$ & \multirow[t]{3}{*}{$87,3 \%$} & \multirow{3}{*}{$\begin{array}{l}\text { Sangat } \\
\text { Layak }\end{array}$} \\
\hline & 12 & 43 & 45 & 45 & 44,3 & 50 & $89 \%$ & & \\
\hline & 13 & 41 & 41 & 46 & 42,7 & 50 & $85 \%$ & & \\
\hline \multicolumn{8}{|c|}{ Nilai Modul Berdasarkan Hasil Respon Siswa } & $84,4 \%$ & $\begin{array}{l}\text { Sangat } \\
\text { Lavak }\end{array}$ \\
\hline
\end{tabular}

\section{KESIMPULAN}

Berdasarkan hasil penilaian oleh tim ahli dan guru, kelayakan modul ekologi berbasis EfSD untuk siswa SMA kelas X mendapatkan nilai rata-rata dengan persentase sebesar 93,3\% dengan kategori sangat layak. Uji respon siswa pada modul memperoleh nila rata-rata dengan persentase sebesar 84,4\% dengan kategori sangat layak. Berdasarkan hasil tersebut, modul ekologi berbasis EfSD untuk siswa SMA kelas $\mathrm{X}$ sangat layak digunakan sebagai bahan ajar untuk siswa dalam proses pembelajaran Biologi.

\section{DAFTAR PUSTAKA}

Abdussakir. (2006). Pengembangan Evaluasi Pembelajaran Berbasis Kompetensi. Retrieved from http://repository.uinmalang.ac.id/1750/6/1750.pdf

Australian Research Institute in Education for Sustainability (ARIES). (2009). Education for Sustainability The role of Education in Engaging and Equipping People for Change. Sydney: Macquarie University.

Badan Pendidikan dan Pelatihan Keuangan (BPPK). (2009). Pedoman Penulisan Modul. Retrieved from http://bppk.depkeu.go.id/id/10283qc4un_165_fhoengljd-qgf0b81-37
Badan Standar Nasional Pendidikan (BSNP). (2010). Paradigma Pendidikan Abad $X X I$. Jakarta: Depdiknas.

Departemen Pendidikan Nasional (Depdiknas). (2008). Penulisan Modul.

Departemen Pendidikan Nasional (Depdiknas). (2008). Panduan Pengembangan Bahan Ajar. Jakarta: Depdiknas.

Dewan Riset Nasional (DRN). (2003). Tantangan dan Peluang Lingkungan dalam Pembangunan yang Berkelanjutan. Jakarta: DRN.

Frijters, S. (2016). Education for Sustainable Development Just do it!. Netherland: AERES University.

Gunamantha, I.M. (2010). Pendidikan untuk Pembangunan Berkelanjutan: Mengapa, Apa, Bagaimana. Jurnal Pendidikan dan Pengajaran, 43(3), 215-221

Hanifah, U. (2014). Pentingnya Buku Ajar yang Berkualitas dalam Meningkatkan Efektivitas Pembelajaran Bahasa Arab. Jurnal Ilmu Tarbiyah At-Tajdid, 3(1), 99-121.

Jiaa, P. (2013). Panduan Penulisan Artikel Untuk Penulis. Retrieved from https://media.neliti.com/media/publicati ons/13388-ID-panduan-penulisanartikel-jiia.pdf 
Kementerian Pendidikan dan Kebudayaan (Kemendikbud). (2016). Education for Sustainable Development. Retrieved from http://kniu.kemdikbud.go.id

Kementerian Pendidikan dan Kebudayaan (Kemendikbud). (2017). Model Silabus Mata Pelajaran Sekolah Menengah Atas/ Madrasah Aliyah. Jakarta: Kemendikbud.

Kementerian Pendidikan Nasional (KPN). (2010). Panduan Peningkatan Kompetensi Pendidik dan Tenaga Kependidikan Nonformal dalam Rangka Pendidikan untuk Pembangunan Berkelanjutan (Education for Sustainable Development) Melalui Pusat Pengembangan dan Tenaga Kependidikan (PPPPPTK). Jakarta: Kemdiknas.

Kementerian Pendidikan Nasional (KPN). (2010). Model Pendidikan untuk Pembangunan Berkelanjutan (Education for Sustainable Development/ ESD) melalui kegiatan Intrakulikuler. Jakarta: Balitbang Kemdiknas.

Kowiyah. (2012). Kemampuan Berpikir Kritis. Jurnal Pendidikan Dasar, 3(5), 175179.

Kuswandari, M., Widha, S. \& Supurwoko. (2013). Pengembangan Bahan Ajar Fisika SMA dengan Pendekatan Kontekstual pada Materi Pengukuran Besaran Fisika. Jurnal Pendidikan Fisika, 1(2), 41-44.

Laksana, D.A.W. (2013). Retrived from http://dinus.ac.id/repository/docs/ajar/T YPOGRAPHY_jenis_karakter_transfor masi.pdf

Muslich, M. (2009). Pembelajaran Berbasis Kompetensi dan Kontekstual. Jakarta: Bumi Aksara.

Nurkamto, J. (2010). Penulisan Artikel Untuk Jurnal Ilmiah. Retrieved from http://jadiwijaya.blog.uns.ac.id/files/201 0/06/penulisan-artikel-untuk-jurnalilmiah1.pdf

Purnomo, D., Indrowati, W., \& Karyanto, P. (2013). Pengaruh Penggunaan Modul Hasil Penelitian Pencemaran di Sungai Pepe Surakarta sebagai Sumber Belajar Biologi Pokok Bahasan Pencemaran Lingkungan Terhadap Hasil Belajar Siswa. Pendidikan Biologi, 5(1), 59-69.
Purwanto, N. (2008). Prinsip-prinsip dan Teknik Evaluasi Pengajaran. Jakarta: PT Remaja Rosda Karya.

Purwasasmita, M. (2017). Storyboard. Retrieved from http://file.upi.edu/Direktori/FIP/JUR._P END._LUAR_SEKOLAH/1947041719 73032-

MULIATI_PURWASASMITA/5_story board.pdf), diakses 17 Oktober 2018.

Rahman, A., Ika, R., \& Indria W. (2017). Pengaruh Metode Field Trip Dengan Pemanfaatan Rumpon Buatan Terhadap Keterampilan Proses Sains Dan Sikap Ilmiah Di Smp Satu Atap Pulau Tunda. Biodidaktika, 12(1), 23-30.

Riduwan. (2010). Belajar Mudah Penelitian untuk Guru - Karyawan dan Penelitian Pemula. Bandung: Alfabeta.

Rosita, I \& Leonard. (2012). Meningkatkan Kerja Sama Siswa Melalui Pembelajaran Kooperatif Tipe Think Pair Share. Jurnal Formatif, 3(1), 1-10.

Sadjati, I.M. (2012). Hakikat Bahan Ajar. Retrieved from http://repository.ut.ac.id/4157/1/IDIK40 09-M1.pdf

Safitri, R. \& Bowo, S. (2013). Biologi: Peminatan Matematika dan Ilmu Alam untuk SMA/MA Kelas X. Jakarta: CV Mediatama.

Santoso, B. (2013). Skema dan Mekanisme Pelatihan: Panduan Penyelenggaraan Pelatihan. Jakarta: Yayasan Terumbu Karang.

Segara, N.B. (2015). Education for Sustainable Development (ESD) Sebuah Upaya Mewujudkan Kelestarian Lingkungan. Social Science Education Journal, 2(1), 22-30.

Sudiana, D. (2001). Tipografi Sebuah Pengantar. Mediator, 2(2), 325-335.

Sungkowo, 2005. Konsep Pendidikan Lingkungan Hidup pada Jalur Pendidikan Dasar dan Menengah. Jakarta: Dikdasmen.

Tilbury, D. \& D. Wortman. (2004). Engaging People in Sustainable Development. UK: IUCN.

Trilling, B. \& Fadel, C. (2009). 21 st Century Skills. San Fransisco: Jossey Bass.

Warsinha, J. (2015). Modul Pelatihan Pengembangan Dan Pemanfaatan Konten Jardiknas. Retrieved from http://www.informatika.unsyiah.ac.id/u mam/mediavideo.pdf 